\title{
AN OVERVIEW OF AIRLAND COMBAT MODELING AND SIMULATION
}

\author{
Michael W. Garrambone \\ Veda Incorporated \\ Wright Point Office Bldg, Suite 200 \\ 5200 Springfield Pike \\ Dayton, Ohio 45431
}

\begin{abstract}
This document presents an overview on one of the most difficult topics of Operations Research-combat modeling and simulation. It describes from a team leader standpoint, the requirements which drive the modeling processes used to support DOD studies. The paper discusses models, (sources and construction notes), scenarios, data, computer concepts, team composition, and many other important considerations needed to accomplish the analytical study tasks. The reader, novice or seasoned, will find that this approach to the subject contains insights rarely found in manuals, covering topics from defining the study environment, to the techniques for presenting study results.
\end{abstract}

\section{INTRODUCTION}

This paper provides an overview of AirLand combat modeling and simulation, with an orientation on what a new study team leader needs to know about operations research modeling, and how to do studies using combat models. The information presented herein has been distilled from some of the best minds in the analytical community, way too many to cite individually, but suffice to say the real experts who truly deserve mentorship credit. This paper is recommended for all readers who haven't been in the combat modeling world very long. For those with considerable experience, I recommend you sit back and enjoy the material, for you will probably read, smile and nod your head, and maybe say yep, I've been there before.

The Environment: Well, the first thing a person should know walking into this modeling business is that this is "no piece of cake" kind of job. It's a tough environment, there are lots of "types" of experts out there, many things are happening, the modeling ship is always moving, and you're expected to keep things on your project going in the midst of all the changes.
I say combat modeling is volatile, because one small change in this field can potentially kill your study. I think that this is important to know, and just this circumstance alone makes the whole field controversial. At some point the question arises as to who's doing these types of studies. Well, nearly every mother's son and daughter is doing combat modeling and simulation somewhere. The total number of agencies involved in modeling could not be summarized on any single chart, with practitioners running from the Army Material Systems Analysis Agency (AMSAA) to the Navy's special study centers. One thing you may want to know is how simulation fits in with the other practicing Operation Research (OR) skills. A survey conducted at the Army Logistics Management College (ALMC), Fort Lee, Virginia indicates that from the Army's operational standpoint about 28 percent of all OR falls in the category of simulation, and I think it is reasonable to say that some percentage of other OR applications such as statistical analysis are probably used in support of simulation studies. The future for modeling and simulation also appears to be bright, in that modeling and simulation can be found on every chart of projected technology programs with military applications. In summary, the field is not going away and it is projected to have widespread future use.

Application Areas: The specific type of modeling and simulation addressed in this paper is combat modeling and simulation, which contains a set of unique types of processes considerably different from say industrial modeling. These processes, which are discussed in the lecture notes of the late Professor James K. Hartman, Naval Post Graduate School, and can be found less clearly in most model documentation, are quite difficult in fact to model. Many of these processes such as intelligence gathering and dissemination, mission assignment, force movement, engagement, attrition, are extremely difficult to capture in models. Professor Wayne P. Hughes Jr. tells 
us in his book, Military Modeling, that models which contain these processes are applicable when looking at problems in battle planning, wartime operations, weapon procurement, force sizing, human resource planning, logistics planning, and national policy analysis-not exactly the list of non-controversial subjects in the Department of Defense.

The Agenda: This paper begins with a brief background/introduction to modeling and simulation, and discusses what the actual study process looks like. After this, models and scenarios are examined, followed by data, everyone's favorite subject. The paper identifies how real analysis works, and closes with some lessons learned from the guys in the field that survived the great study wars.

\section{SOME TERMS}

Combat modelers must be familiar with a considerable number of modeling terms, or be able to state their own "user-controlled" definitions. The terms verification, validation, certification, corroboration, and accreditation are always "test questions" and requests for these definitions always require solid responses. Two less well known definitions pertain to model data and define circumstances which you are most likely to run into. Sometimes you are going to have to get on the phone and ask someone to help you get data. If they say something like, "You can use this information but please don't credit me with it.", then you have received what is considered to be the "non-attributed hack". The second term acknowledges that you will have to feed your model the data you currently have in order to finish your study on time. Knowing full well others are producing new data which will be available in time to confound your results, you must identify the data you are using as best available data or "BAD" data since this is always the type data which goes into combat models.

\section{THE PLAYERS}

As in any professional encounter, one must know who the players are. First off, there are the agencies which consist of boards, committees, societies, and educational institutions which set policy, identify procedures, and frequently provide funding for model usage. Then there are the model proponents, these are agencies who own or maybe just oversee the models. Next comes the "enhancers" and fixers. These are the essential people who make models study-ready, but have a tendency to look at the model as an art form which requires total revision before being revealed to the public. The most important player in the game is the model user or study team leader who must efficiently and effectively use this tool to assist decision makers. Next on the list are the model advocates and adversaries. Both the advocates and adversaries recognize the strengths and shortfalls of the models, and may actually switch sides depending on who is being tasked to do the study. The true winners in the modeling community are the contractors for they retain institutional knowledge, propriety code, the ability to get smart quickly, and can generate numerous unsolicited project proposals. Last, but far from least are the data boys. These people are the dependent variable in studies. If these people are not on your side, you don't have a study, but more about data later.

\section{THE STUDY PROCESS}

Well, what should you know about studies in general? Most institutions emphasize the standard study approach consisting of six to ten steps which begin with the definition of the problem and end with communicating the results to the decision makers. The true combat study game plan actually consists of two ongoing processes of analysis and modeling efforts.

\section{ANALYSIS}

Define the study

Research the field

Determine Feasibilities

Develop the study design Analyze results

Perform sensitivity analysis Document \& report findings

\section{MODELING}

Acquire the computer model Spin up on the model use Acquire and implement scenario Update the model data Develop software tools Enhance model where necessary Run the study matrix
In theory, one begins on the analysis side of the chart and begins to work his or her way down the list of activities until at some point (probably after the "develop the study design" step) it is time to beginning executing the modeling activities on the right side. After finishing these modeling activities, one then returns to the analysis activities to finish up the "classic study." While this is typical of how studies are suppose to be done, I believe this example is rarely the case since some activities on both sides can be accomplished in tandem. In fact, I have seen people start on the right side of this chart and roll over to the left side in accomplishing their studies, but I really wouldn't recommend that. Because study projects must be carefully managed, it may be required to prepare a very impressive Gantt chart to show the boss what is going on. A chart consisting of the activities of front end analysis, study plan development, model building, model revision, simulation, documentation and briefings, and final report writing keeps everything in prospective. This chart has the appeal of indicating everything is in the right sequence and accounts for the activities which are necessary for finishing the project on time. Unfor- 
tunately, you can expect most of the activities listed on your chart to take fifty percent more time than planned, and that the chart will end up looking like seven parallel bars. You will then need to glue another sheet of graph paper on the right side of the chart to show the additional time required to rerun the simulations, revisit new contingency questions, design and perform the additional unforecasted yet required briefings, and to rewrite and publish the final "final report."

\section{MODELS AND SCENARIOS}

Having taken on the study task, one must acquire the two ingredients required to make the project work. If you are doing a combat study, you will probably need a combat model, and in these days of "jointness", an AirLand Battle scenario. You, as study leader, are responsible for getting these things. If you know your way around the modeling community, you can get help provided you have developed your own little network of practitioners.

\subsection{Models}

Fortunately, all models look the same. On the left side of model diagrams are the kinds of information which must be fed into the models to get them to work properly. This information generally consists of weapon/unit data, operational or doctrinal data, environmental data, and finally the model scenario itself. To make life easier a preprocessor program (which is always an optional purchase) can assist in constructing, editing, screening, and formatting the required information into the proper "simulation ready" files. After putting all the input information together, one merely turns on the simulation pump and grinds out the first raw forms of output. These output files could contain key decisions made by the combatants during the simulation, status reports over time, and attrition and logistic statistics. Now, prepare to spend the rest of your life working on the volumes of data trying to figure out what all this output means. Fortunately again, you can acquire a postprocessor program which can help you extract only the pertinent data you require within selected boundaries (time of battle, unit specific or weapon specific categories, or by supply class etc.) and codify it in various ready-for-presentation formats. On the other hand, if you do not have a postprocessor, or the one you do have does not generate or format the data you are specifically interested in, you can build, or "outof-house" buy one. Be sure to lengthen the analysis activity on your Gantt chart for this circumstance.

\subsection{Sources for Models}

Most agencies only modify the models they use for studies, that is, very few agencies actually have the time and resources to build new models. Therefore, avoid if you can developing a new model, for it is nearly always better to borrow someone else's model (and their data if possible) for you will be able to perform your study faster and will always have someone to sympathize with when things go uncontrollably wrong. Now, the question is where do you find out about existing models, and how do you get hold of one with which to do your study? Well, the first and most famous place to look for models is in the J-8 Catalog of Wargaming and Military Simulation Models. The new twelfth edition catalog published this year contains 528 different models and their descriptions. You can obtain this catalog through the Defense Technical Information Center (DTIC) at (703) $274-7633$ or call and obtain the information on floppy disks. I recom-. mend you obtain a hard copy of the 11th edition of the catalog (DTIC number AD-A213970) for it contains a model classification system worth its weight in gold. The J-8 is not the only place to find models. If you really get desperate and you are in the Air Force, you can go to the Air Force Center for Studies \& Analyses since they have a whole stable of models which are very useful. Down at Wright-Patterson AFB is SURVIAC, a model clearing house which dispenses Air Force and Air Defense type high resolution and engineering models. For the Army guys, I recommend scanning the Inventory of TRADOC Models and Simulations Catalog for AirLand Battle type models. For those interested in wargames, I suggest getting hold of the ABCA Catalog of Wargames provided by Mr. Walter W. Hollis, the DUSA(OR), or the Wargaming Bibliographic Series published by the folks at Air University, Maxwell AFB, Alabama.

\subsection{Model Schema}

Now let's assume you have found and obtained from the proponent the computer model, or its beta version. A beta version is a new untried version of the model issued by the proponent. This version supposedly contains the new capability you need right now for your study, which you may obtain, provided you are willing to forego bad-mouthing the providing agency should anything go wrong with the code. Within any model's user manual, the first thing you will notice in the model diagram, in the center of the page, is a block labeled the computer model. This block represents the model's computer code in its general form. To the left of the code block is the input block which contains three special input items. They 
are: the model run instructions, iteration counters and statistical flags, the model data, and last, the particular scenario file which drives and characterizes this unique simulation. Users typically refer to the combination of the input items and the computer model code as the "combat model." The computer programmers look at the same two items, raise their noses and say, "It is all data, just data as far as we're concerned.", and continue to grow their hair. A third block on the rights side of the diagram contains the recorded results of exercising the combat model, that is, the results of the model simulation run based on it's unique input items.

\subsection{Scenario}

It is clear that in order to get the model to run one will need lots of data, various model operating instructions, and most importantly this thing called scenario. I will forgo at this time the issue of how one gets the scenario into the computer model, but as a study leader you may find the answer to this question to be a study show stopper-beware! A scenario is basically an outline of a hypothetical/conjectured or projected chain of events. The contents of a scenario are most important to the study since they define the combat environment, identify the principle and subordinate forces, outline the intentions of the combatants, unveil mission objectives, contain operational, tactical, and contingency orders, and shows the planned use of resources, be they maneuver, fire support, or logistical in nature. The scenario for a combatant may contain default or standard operating procedures, plans of reconstitution for units, and the concept of what may be the force's defeat conditions. In short, the scenario contains the thought process of what the game plan was suppose to have looked like when it was originally designed. It doesn't define exactly what every force is going to do, but contains more of a situational awareness of the circumstances of the battlefield and the commander's desire on how he wants to fight the battle. The scenarios required for engagements of large or joint forces are relatively complex to design. To construct scenarios of this magnitude would require the collective backgrounds, experience, and judgement found in only senior battle staffs with complete intelligence and operational planning cells (or by any Army major graduating from the US Army Command and General Staff College, just kidding). At the campaign planning level, scenario designers are expected to portray the collective thinking of hundreds of combat commanders. This is why large scenarios are typically designed by groups of senior officers of various branches and services, and reviewed at the general officer-level. You can imagine the amount of tactical and technical information that a scenario draws upon. Now, if you are sitting in your office and you have the ability to portray all the thought processes of these many staffs and commanders at one time, you can write your own scenarios. Personally, my experience at orchestrating corps, divisions and numbered air forces has been rather limited, and besides I'm tired at being seconded guessed by all those guys on CNN. Never-the-less, in order to get the model to run you will need a scenario. My first experience with scenario problems came when I was assigned to a team which had been already running their study matrix with a scenario that came free with the model code. Fortunately, when I discovered that the doctrine used in the model was pre-AirLand Battle we "only" lost four months of our study time in analyzing scores of useless runs.

\subsection{Scenario Requirements}

If you are the study leader, you must be sure that the scenario fits your study objectives. If you are trying to determine if something (like a new weapon system) makes a difference, then you will have to have a scenario that affords an opportunity for that difference to be demonstrated. You would expect a model which contains a brief (say 5 minute) battle time scenario to provide very little logistics information, or an air defensive weapon to show any improvement in rear area survivability when the scenario is limited to only battalion-level operations. Regardless of your agency size, you must select a scenario which is "doable" within your resources. This means that the scenario must be either of the correct size, or can be shrunk to fit the study. You must be able to acquire, convert, or reformat the scenario in time for it to not adversely impact on your study timetable, and that the accompanying systems data be consistent with the planned application years of the scenario. Remember, most scenarios are constructed for application in the out years. This means that someone has to predict what the weapons systems and doctrine will look like in ten or fifteen years from now. This requirement alone will make it difficult for you to get scenario compatible data. There are a few people to whom you can go to obtain this kind of information, but to some degree they too are only guessing. To get a feel for the problem, picture in your mind the engineering characteristics and how you will fight the main battle system in the year 2015. You can see, that you are only going to get so close with your estimate. The best thing to do is to ask some agency to 
support your search and document the information they provide. This in the end, will save your butt.

\subsection{Combat Factors}

Now, what should you be looking for in a scenario? $\mathrm{Be}$ on the lookout for the basic factors of combat power. Besides maneuver and fire support, you might include, electronic warfare, logistical support, psychological operations, intelligence, battlefield disposition, deception, weather, battlefield mobility, engineers, and terrain. It would be nice if you could get scenarios with all these factors being played. Don't count on finding these types of scenarios yet, but people are working on them.

\subsection{Scenario Sources}

So where does one get a hold of those ready-made scenarios. In the Army, we just go to TRADOC, the Army's Training and Doctrine Command. It is a little different if you are in the Air Force. I've asked several high ranking people in the Air Force, "Where do you get your scenarios?" They said, "If you want a MAC scenario you go to MAC, if you want a TAC scenario you go to TAC." I said, "Well shoot, don't these guys ever get together on one scenario?" They said, "No, why should they?" At this point I figured that getting an Air Force scenario was going to be tough. When I went to the Pentagon and asked, "Where do you get your scenarios?" they said, "Well, you tell us first where you get yours." So I told them TRADOC Regulation 71-4 identifies who in the army is responsible for scenario development. I said, "We have whole general officer study groups that make up our scenarios. I mean these scenarios are drawn up, pounded out, and approved at every level before they ever get out on the street for agency use." I think this is a good idea to spread around so that eventually everybody might begin to do the same thing. I realize ideas like this must be shared with our relatively junior sister services.

\section{DATA}

Well, we've talked about scenarios, now we have to beat that other demon to death, the model data. You may not know it but data is owned by ogres. These people are pocketed all over the country and they hoard the stuff you need to do your study. I used to show my ogre slide at general officer meetings until and one gentleman pointed to the fellow on his left and said, "Gee Dan that beast up there looks a lot like you." The fact remains that good data is hard to get. What kind of data might you be looking for? Well, the categories may include doctrinal, operational, organizational, weapon system, terrain, and equipment data. Data can also be obtained on historical or projected unit performance, on command, control, communication, intelligence functions, or on logistics issues. As a study leader, you have got to find a source from which you can gather this type of information. Be aware, you may have to reach quite far to find your data, and it may take a long time before you have in hand.

\subsection{Data Sources}

Now, where can you go to get good data? Here is a list of several different agencies which are repositories for both US and threat data. For US data, you should try the major operations and personnel staff agencies, combined operation and military integrating centers, the service's analytical agencies, the service schools, the material commands, world-wide operation research cells, and the wargaming centers. The Warrior Preparation Center is a good source for unit basic load data which is the need-to-know stuff because it affects nearly every sustaining issue in battle. When units go to the Warrior Preparation Center, they are required to input basic load information into the wargames. If you can get access to these machines, you may be able to get a copy of all these basic loads thereby solving one horrendous data gathering problem. Now, what about red or threat data? Here, you must go to all the IA's (intelligence agencies), the foreign technology centers, and even material and operational testing agencies. The mission of these agencies is to find out what the other guy should look like now and in the future. Those who have beaten the data path have found threat data to be easier to obtain than blue (US) data. I can only guess why this is true, but unfortunately using threat data requires getting some consensus among these agencies. Despite the fact they are all in the same business, the same question asked of these agencies will rarely get you the same answers. It really makes me wonder. I believe that if I could get all the experts from these agencies together in one room, and I said, "Look up there on the wall, what time is it?", one of those guys would say, "Hey, is that an agency approved clock?"

\subsection{Terrain and Human Factor Data}

Everybody knows that you can get terrain data from DMA, the Defense Mapping Agency. Yet, DMA is not the only place out there that has terrain data, besides they're terribly overworked and it may take you forever to get it. You can also acquire data 
from the Engineer Topographic Labs, the US Military Academy, and Rome Air Development Center. I would highly recommend WES, the Waterways Experiment Station, who work for the Army Corps of Engineers as a good source. Those engineers are a hell of a bunch of good guys. If you are interested in what happens underwater or at the seashore, NORDA, the Naval Oceanographic Research and Development Center is the place to go. Human Factors data can be obtained from several sources including The Army Research Institute (ARI), The Army Human Engineering Laboratory (HEL), and CERIAC, the Crew System Ergonomics Information Analysis Center, hosted by the Air Force's Armstrong Aerospace Medical Laboratory.

\section{ANALYSIS}

If at this point you've got the input side of the model nailed down and you have done the simulation, then it is time to figure out what happened based on the model output data. You are at the back end of the game now, and must assess what you have. Keep in mind, a lot of stuff comes out of those machines, but it needs to make sense to general officers who are thinking about the big heavy high-priority topics. Make sure that what you are telling them is relevant to what they are interested in. If you want to blow a study this is a good place to mess up. You may find that the information you are seeking from the model may not even be available. That is, I've never seen a model that gave me exactly what I wanted. I had a combined arms study in which I asked how often requests were made for artillery support during the battle. My contractor personnel said they didn't really know. I said, "Look, doesn't this model play fire support, doesn't it play artillery?" They said, "Yes it does, but nobody ever wanted to know how often it is requested, and so that information is not available as standard output of the model." It cost us about a weeks worth of programmer time to find the answer to my question, but it seemed to me to be an important issue if you were studying artillery effects in battle. Beware that there will be some new code development as part of your project, fore the models never have exactly what you want in the format you are looking for. You will probably pay with some time to get at these answers.

\subsection{The Presentation}

A major issue in your project is to determine if the output results are significant. This may be tough to determine, but if your analysis passes the "so what" test, then you must next try to ascertain causality for these results. It is crucial that you understand that "you" knowing what is going on is just not good enough. As an OR analyst, you must pass this information on to someone else and it has to be in the form where the other guy says, "I can see it, it's clear to me, I know exactly what you are talking about." If your transfer of information does not meet this criteria, your analysis is going down the tube. As Mr. Hollis once said, "No significant decision was ever influenced from analysis which was never understood." This is one of those important ideas which you need to focus on during your study.

\subsection{Measures of Effectiveness}

Now, what kinds of things do people traditionally look at on the output side of models, the measures of effectiveness, or MOE's if you will. Here is a list of the common ones, FLOT movement, unit status, and various ratios. I know you're thinking about that black hole up on the chart, the killer-victim scoreboard. Everyone thinks they can understand the scoreboard, but in reality there are over 15 sand traps in evaluating this type of table that you should be aware of. If you call me at (513) 476-3516, I'll send you a copy of these traps. Meanwhile, don't ever show a scoreboard in a briefing if you can avoid it, otherwise, prepare for widespread interpretations.

\section{MODELING BARRIERS}

If you're going to get into modeling, you need to know about some of the barriers you will run into. First off, the models are complex and this alone causes them to be viewed in an atmosphere of rejection. You have heard me talk about data already. But occasionally people call you about data. The phone rings, someone says, "Hey, you know that data I sent you on the tape last week, Well I know you wanted PK data, but I gave you the wrong tape, what you have now is the can count at the commissary data." You start thinking, "Boy am I in trouble, I've been getting some pretty good results off of that data." Another problem you may run into is the perception problem. All models are just models, that is, they only capture so much of an actual system's characteristics or operations. All models have some problems, but if a model has a reputation as "suspect" and is measurably improved by all standards, it will still have this bad reputation. The model will not be readily accepted for use in studies without considerable advertising and demonstration of the improved capabilities. This next bullet speaks to the issue of relevance. If 
the model output is perceived as not having an impact, the model is dead in the water. And lastly, agencies would prefer not to use someone else's model.' There is always a hesitancy to take on the task of understanding other modeler's code, data requirements, and clever work-a-rounds. "Not invented here" has on occasion blocked the use of good existing code, and has produced many new in-house modeling projects.

\subsection{The TRADOC Inquisition List}

If you are doing modeling and simulation for TRADOC you are going to get hit with this inquisition list. Be ready to describe how your model plays C3I and the doctrinal differences between opposing combatants. You will be asked about the attrition phenomena and suppression effects as well as how human factors are incorporated into the model. An important factor in studies is the battle time to clock time ratio. The bigger combat models require large run times and you may get to the point where the model is impractical to be used in a study because it just takes too long to run, or too long to run the needed number of iterations. Where did you get the input data is a question you must be ready to respond to. You can answer "from all the usual suspects", but it is better to have a hit list of agency sources. The last item of interest is documentation. I have found the status of model documentation to run from fictitious to erroneous. This item of business is traditionally financed last, if at all, and impacts most, only on the "next" users study.

\section{LESSONS LEARNED}

What I will discuss now is a series of lessons learned. Right off the bat, you will find it takes a long time to learn about and set up the computer model, verify the data, and draft up the scenarios. The simulation itself is relatively quick to run, but where you start paying "bigtime" is on the analysis end. These ideas need to be briefed to your study sponsor as well as the circumstance that no two subject area experts will agree 100 percent on anything. The documentation you will use, will usually be at best incomplete, inaccurate, and confusing, therefore, you must network with user groups to survive. Before you run your "study model", you must construct a well understood "base case" which is prepared in an iterative process of quality assessments and revision until the time runs out. Be mindful that somebody somewhere will not like your model and the only thing you can do is go see that person (what we refer to in the Army as foot coordination) and find out their form of un- happiness. If you can make him happy, fine. If you can't, you still have to do the study, but you will have created a better peer review, and professional understanding atmosphere for your work.

\subsection{Time}

I mentioned this before, and I think study leaders need to be constantly reminded of this, that is, the models are built to the clock's standards. This means that when you hit your ready-to-run milestone, that you must go with it. You can always calibrate (tweak is a bad word) and make it better, but providing model results after the decision is made is fruitless. Be careful of seeking more realism in models. More realism means, more code, more data, more time, and a need for a greater level of analysis which you may not be able to live with. You may at times have some outstanding model questions. From the Corps of Engineers perspective, these questions are like tricky land mines, in that beneath every one of these questions that you defuse, there is another question just waiting for you.

\subsection{Study Performance}

People have talked a long time about how models operate. The key thought is that stochastic models provide variations on how the battle might have occurred. Models do not say this is the way things are going to be, they say, under the circumstances, this is sort of how this one fell out. You can make any model combatant execute a "perfect" game plan by scripting every single thing that you want to have happen in the scenario. This can be accomplished by scripting, running, analyzing, and rescripting until the unit's performance is as close to being exactly what you want it to be. This process could take a very long time to accomplish and therefore models with automated command and control features are nice to have. As for battle analysis, this remains a difficult task to accomplish despite the use of postprocessors, spreadsheet, and sophisticated database managers. If you had to put together a brand new team for a very big study, I would say that in order to get your team study ready, tactically prepared, analytically smart, and model knowledgeable, and get the study done, could take you up to 3 or 4 years. That is why most agencies have a steadfast cadre of seasoned analysts, programmers, statisticians and the like and can make the 6 month to 2 year turn around time required of most studies. To create a fully proficient combat modeling and simulation analyst takes from one year to forever for most of the large combat simulation models. Sometimes a model run doesn't seem 
to be working quite right. Don't jump to conclusions right away about the quality of the model. It may not be easy, but it is better to track down the cause of your concern and learn quite a bit more about the model. In one instance, I had a unit conducting a battle, where for one run, in a period of minutes it lost 60 tanks that it had never lost in runs before. I looked, and looked, and looked, but couldn't figure out what happened, or why these tanks were lost. It was sometime later when I found out that this run was the only time somebody shot out the ammunition unit that was supplying those guys. Essentially what happened is that they stayed alive because constant resupply kept them lethal, whereas in this single case the groceries just didn't arrive-an insight as to the importance of logistics. In another case, my helicopter attack did not execute although the unit was on standby and combat ready. In this run, the headquarters that should of issued the command for the helicopters to move was under attack, and was unable to pass the attack order. The lesson here is to look at the odd results, for even these weird outcomes do have their special meanings. Remember, you are searching for trends not numbers, and ideas not necessarily answers.

\subsection{Practical Thoughts}

From a practical standpoint it is not worthwhile to always second guess the output of a model run, it is faster to just go ahead and run it. If you want to check things out, do sensitivity analysis by running small scenario vignettes. As the study leader, you will be dependent on you computer support. If the "beast" goes down you are in big trouble. I was stationed in Albuquerque, New Mexico and I was looking for a corps-level combat model. In my search, this fellow offered me a model which ran with a ratio of 1.1, computer time to combat time. I asked him if I was to run a 60 hour battle would it take me 66 hours to get the results. He said, "That's right." I told him in Albuquerque we don't get continuous electricity for 66 hours, and I just couldn't use that model. You can see that combat simulation requires extensive military modeling expertise. I caution you at this point that modelers become immersed in their work; remember, THE MODEL IS NOT THE WAR!

\section{VALIDATION}

Next, I would like to tell you what decision makers have been told are techniques for validating models. You can see that comparing model results with actual field data is hard to beat. When the arguments start, you can say, "Well here is my data, where is yours?" You are bound to win on this one. A second technique, getting independent reviews of your model by peers and subject area experts is probably the best method of gaining some appraisal on the model. Asking for expert judgement or comparing model results to historical data are considered acceptable techniques in many circles. The last technique, comparing your output to that of other models, has been used in the past to validate from validated models, but this fast becomes a chicken or the egg issue. The real issue nowadays is accreditation, get Army Regulation 5-11.

\section{REALITIES}

Some of the realities of combat modeling and simulation are that: it is complex and just plain hard to do (remember, we use simulation when all other techniques fail), it is done in a competitive environment, it consumes enormous hidden technical, administrative and informational resources, even the experts vehemently argue about everything, it requires personnel of immense and focused dedication, it takes time to learn (but depth is career de-enhancing), and it often requires biting the bullet. Unfortunately, the bullet is moving, and it is a 155 round.

\section{SUGGESTED READING}

So what can you do to help yourself get smart? Well you can start by doing a lot of reading. I suggest you read the three famous GAO reports on DOD simulations. They are: GAO Report B163074, "Advantages and Limitations of Computer Simulations in Decisionmaking", PAD 80-21, "Models Data and War: A Critique of the Foundation for Defense Analyses", and GAO Report PEMD-88-3, "DOD Simulations: Improved Assessment Procedures Would Increase the Credibility of Results". These documents will tell you what has happened in the past and probably what to avoid in the future. Read modeling, simulation and wargaming publications by Battilega and Grange, Wayne Hughes, Brewer and Shubik, Callahan and Galiano, Parry, Clark, and Allen. Read anything by Dunnigan, Depuy, SunTzu, Napoleon, Clausewitz, Paret, Perla, Lanchester, Hartman, and Shaw. Get hold of simulation analysis publications from Shannon, Law and Kelton, and Pritsker. Strengthen your phenomena understanding with DARCOM Pam's 706-101 and 706102, "Army Weapon System Analysis" and get your mathematics in check with Taylor, Ancker, Bonder and Farrel, Bauer, and Przemieniecki. Better yet, 
take Garrambone's Combat Modeling and Simulation Courses, they will kill you.

\section{GARRAMBONE'S CHARACTERISTICS OF THE SUCCESSFUL COMBAT MODELER}

Over the years I've come up with a list of characteristics of successful combat modelers. These are people with in depth tactical, technical, and historical combat knowledge. They are academically sound and professionally astute operations research analysts. Despite the rapid changes in the field, they are masters of computer science wizardry. They have outstanding communicative and interpersonal skills along with superb artistic and graphical talents. Above all, they possess overwhelming quantities of persistence and determination. As you might imagine, it is quite difficult for any one person to be all of these things. In fact, it might be impossible to find these attributes in any forum of single subject area experts. The thought here is the same thought that historically created the original operations research groups, that is, to group together people of strong but diverse talents to attack complex and difficult problems. As the study team leader, you also must develop this team building and team performance approach, for this too is your key to success.

\section{THE CLOSE}

This modeling and simulation stuff is a tough gig. I remember how I found out I was a combat modeler. It was when I took my son in for a haircut. He said to the barber, "I want a hair cut just like my Dad, see if you can cut an "M " into the front like he has." Thank you for your time.

\section{AUTHOR BIOGRAPHY}

MICHAEL W. GARRAMBONE was the Army Instructor of Operations Research at the Air Force Institute of Technology, Wright-Patterson AFB, Ohio, where he taught graduate courses in Combat Modeling and Simulation, and Human Factors Applications in Operations Research. During his career he had a number of assignments in which he was involved in both the development and applications of computer modeling and simulation. He is currently a Senior Analyst at Veda Incorporated, Dayton, Ohio, and remains an active member of MORS, ORSA(MAS), AORS, and Omega Rho. 